\title{
Growth of Single-Walled Carbon Nanotubes Using Germanium Nanocrystals Formed by Implantation
}

\author{
T. Uchino, ${ }^{\mathrm{a}, \mathrm{z}}$ G. N. Ayre, ${ }^{\mathrm{b}}$ D. C. Smith, ${ }^{\mathrm{b}}$ J. L. Hutchison, ${ }^{\mathrm{c}}$ C. H. de Groot, ${ }^{\mathrm{a}}$ and \\ P. Ashburn ${ }^{\text {a }}$
}

${ }^{a}$ School of Electronics and Computer Science and ${ }^{b}$ School of Physics and Astronomy,

University of Southampton, Southampton SO17 1BJ, United Kingdom

${ }^{c}$ Department of Materials, University of Oxford, Oxford OX1 3PH, United Kingdom

This paper presents a complementary metal oxide semiconductor compatible method for the chemical vapor deposition of singlewalled carbon nanotubes (SWNTs). The method uses Ge implantation into a $\mathrm{SiO}_{2}$ layer to create Ge nanocrystals, which are then used to produce SWNTs. The results of atomic force microscopy and scanning electron microscopy analyses indicate that Ge implantation provides good control of particle size and delivers a well-controlled SWNT growth process. The SWNT area density of $4.1 \pm 1.2 \mu \mathrm{m}$ in length $/ \mu \mathrm{m}^{2}$ obtained from the Ge nanocrystals is comparable to that obtained from metal-catalyst-based methods used to fabricate SWNT field-effect transistors. A carbon implantation after Ge nanocrystal formation significantly enhances the process operating window for the growth of the SWNTs and increases the area density. (C) 2009 The Electrochemical Society. [DOI: 10.1149/1.3147248] All rights reserved.

Manuscript submitted September 17, 2008; revised manuscript received May 5, 2009. Published June 10, 2009.

The excellent electrical, ${ }^{1,2}$ optical, ${ }^{3}$ thermal, ${ }^{4}$ and mechanical properties of carbon nanotubes (CNTs) have spurred the development of several practical applications including field-effect transistors (FETs), ${ }^{2}$ nonvolatile random-access memories, ${ }^{5}$ via interconnects, ${ }^{6}$ field-emission displays, ${ }^{7}$ and sensors. ${ }^{8}$ For applications such as sensors, compatibility of the growth method with $\mathrm{Si}$ front-end processing is highly desirable as it provides additional flexibility for creating a manufacturing process for CNT smart sensors fully integrated with complementary metal oxide semiconductor (CMOS) circuitry.

CNT growth traditionally involves the use of transition-metal nanoparticles as a catalyst. However, the integration of CNT synthesis based on metal catalysts with a standard front-end CMOS process is very problematic due to cross contamination. Transition metals, such as $\mathrm{Ni}$ or Fe, create deep-level defects in the bandgap of $\mathrm{Si}$ and result in unwanted trap states. ${ }^{9}$ If metal-catalyst-free growth of CNTs were available, it would increase flexibility in the device fabrication process. A further requirement for a CMOS-compatible growth method is that it should also be based as far as possible on existing $\mathrm{Si}$ processing techniques to speed up its integration into manufacturing facilities.

At least four different nonmetallic materials have been shown to enable the formation of single-walled carbon nanotubes (SWNTs). ${ }^{10-14}$ The first of these is $\mathrm{SiC}$, which has been shown to work both in the form of macroscopic flat substrates and nanoparticles. CNT growth from $\mathrm{SiC}$ requires either high temperature anneal or laser anneal around $1700^{\circ} \mathrm{C} .{ }^{10}$ The second material shown to produce CNTs was carbon nanoparticles. ${ }^{11}$ While bundles of SWNTs have been produced using carbon nanoparticles, Raman spectra suggest that the SWNTs are structurally defective and that the bundles of nanotubes produced this way may not be suitable for many electronics applications. Both of these methods differ from more standard metal-catalyzed growth in that the source of carbon for the formation of the SWNTs is the catalyst material itself instead of a carbon-containing gas. We have previously published a method for growing SWNTs on SiGe islands or Stranski-Krastanow Ge dots using a standard chemical vapor deposition (CVD) process with growth temperatures down to $850^{\circ} \mathrm{C} .^{12,13}$ This work has recently been supported by the results of Takagi et al. ${ }^{14}$ on the growth of SWNTs from $\mathrm{Si}$ and $\mathrm{Ge}$ nanoparticles on $\mathrm{SiC}$ substrates. While the area density of SWNTs achievable via this method is not given explicitly, it is stated as being low, which may limit this method's applicability.

In this paper we present a CMOS-compatible CNT growth

z E-mail: tu@ecs.soton.ac.uk method, which uses Ge nanoparticles to seed the SWNT growth. The Ge nanoparticles are produced using ion implantation, which is a standard process that is widely available in $\mathrm{Si}$ foundries. This growth method is compatible with front-end Si CMOS technology and hence gives complete flexibility in integrating CNT sensors with CMOS circuitry. It is also the nonmetal catalyst growth of SWNTs in which no solid carbon is intentionally present in the catalyst or substrate. The area density of SWNTs achieved with this method is comparable to that achieved with similar methods based on iron nanoparticle catalysts.

\section{Experimental}

Ge nanocrystals were formed by implanting $\mathrm{Ge}$ into a $\mathrm{SiO}_{2}$ layer and annealing in a $\mathrm{N}_{2}$ atmosphere. ${ }^{15}$ Silicon 4 in. wafers [p-type, (001), 17-33 $\Omega \cdot \mathrm{cm}$ ] were employed as a starting material and 30 $\mathrm{nm}$ thick oxide layers were thermally grown after fuming nitric acid clean. Subsequently, the oxide layers were implanted with $\mathrm{Ge}$ at a dose of $5 \times 10^{15} \mathrm{~cm}^{-2}$ and an energy of $20 \mathrm{keV}$. Then the wafers were annealed in $\mathrm{N}_{2}$ atmosphere at $600^{\circ} \mathrm{C}$ for 40 min to create $\mathrm{Ge}$ nanocrystals. This step was followed by HF vapor etch to remove the $\mathrm{SiO}_{2}$ and expose the Ge nanocrystals formed during $\mathrm{N}_{2}$ anneal. Selected wafers were implanted with carbon at a dose of 3 $\times 10^{16} \mathrm{~cm}^{-2}$ and an energy of $30 \mathrm{keV}$ after the Ge nanocrystal formation because our earlier work ${ }^{12}$ showed that a carbon implantation was necessary for the growth of CNTs from SiGe islands. All substrates were prepared under clean room conditions.

CNTs were grown using a two-step growth process. The first step was a hydrogen preanneal performed at a temperature between 850 and $1100^{\circ} \mathrm{C}$ and the second step was CNT growth by thermal CVD performed in a hot-wall reactor at atmospheric pressure. The wafers were cut in $5 \times 7 \mathrm{~mm}$ pieces to suit a 1 in. diameter furnace tube. The CNT growth was carried out using a mixture of methane (1000 $\mathrm{sccm})$ and hydrogen $(300 \mathrm{sccm})$ immediately after the preanneal in hydrogen $(1000 \mathrm{sccm})$. The preanneal was performed at a temperature between 850 and $1100^{\circ} \mathrm{C}$ for either 5 or $10 \mathrm{~min}$. The growth was carried out at a temperature between 850 and $1000^{\circ} \mathrm{C}$ for 20 $\min$. The furnace was used exclusively for this work to avoid metal contamination.

The Ge nanocrystals were characterized using a Veeco MultiMode atomic force microscope, using supersharp Si tips (typical tip radius of $2 \mathrm{~nm}$ ). The synthesized CNTs were observed by fieldemission scanning electron microscope (JEOL 6500F) and transmission electron microscope (JEOL 3050 and JEOL 4000HR). Transmission electron microscopy (TEM) sample preparation consisted of scraping the sample surface with a surgical blade and transference onto a carbon-coated $\mathrm{Cu}$ grid. The chemical compositions of scanning electron microscopy (SEM) and TEM samples were analyzed 

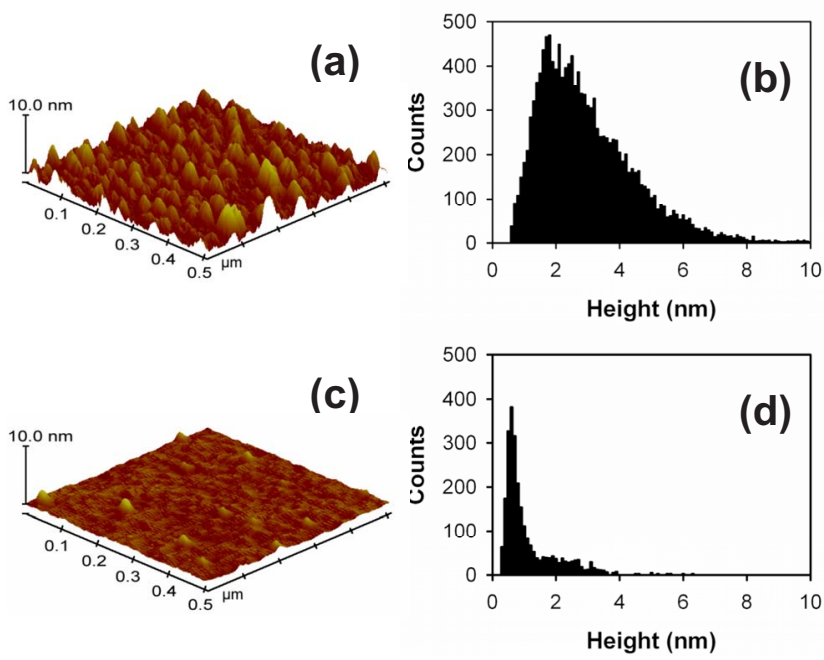

Figure 1. (Color online) (a) AFM image and (b) a histogram of height distribution of Ge nanocrystals produced by $\mathrm{Ge}$ implantation $(20 \mathrm{keV}, 5$ $\times 10^{15} \mathrm{~cm}^{-2}$ ) into $30 \mathrm{~nm}$ thick $\mathrm{SiO}_{2}$ layers and a postanneal at $600^{\circ} \mathrm{C}$ for 40 min followed by HF vapor etch to expose the Ge nanocrystals. (c) AFM image and (d) a histogram of height distribution of Ge nanocrystals for samples given a carbon implantation $\left(30 \mathrm{keV}, 3 \times 10^{16} \mathrm{~cm}^{-2}\right)$.

by energy-dispersive X-ray spectroscopy (EDX, Oxford Instruments INCA microanalysis system). The area densities of CNTs were evaluated using the field-emission scanning electron microscopy (FESEM) images. We used ImageJ to determine the total contour length of CNTs. ${ }^{16}$ For quantitative analysis, several images taken from the same sample were used, with overlapping regions being discarded. Raman spectra were obtained using a Renishaw microRaman system with $\mathrm{He}-\mathrm{Ne}(632.8 \mathrm{~nm})$ laser excitation with a power of $12 \mathrm{~mW}$.

\section{Results and Discussion}

Figure 1a shows a typical atomic force microscopy (AFM) image of the Ge nanocrystals formed without a carbon implantation. These samples showed a high density of particles of different sizes with a mean particle density of $460 \pm 30$ particles $/ \mu \mathrm{m}^{2}$. Figure $1 \mathrm{~b}$ shows a particle height distribution for eight images taken from the same sample. This result shows that the half-maximum counts of the particle height lie between 1.3 and $2.9 \mathrm{~nm}$. This result agrees with others, for instance, Min et al. ${ }^{15}$ reported the formation of Ge nanocrystals, by a similar process, with an average size of $1.9 \pm 0.8 \mathrm{~nm}$. Some of the nanocrystals seen in Fig. 1a are considerably larger than $2 \mathrm{~nm}$, indicating aggregation of the nanocrystals into larger clusters.

A typical AFM image of Ge nanocrystals, also formed after a $600^{\circ} \mathrm{C}$ anneal, with a postanneal carbon implantation is shown in Fig. 1c. These samples show a lower particle density than those without the carbon implantation, in this case $64 \pm 18$ particles $/ \mu \mathrm{m}^{2}$. We believe that the carbon ions sputter the Ge nanocrystals from the surface, thereby lowering their density. Line analyses also show that the surface of the Si substrate is rougher in carbon-implanted samples than in nonimplanted samples. The particle height distribution for 10 images taken from the same sample is shown in Fig. 1d. The modal height is approximately 0.7 $\mathrm{nm}$, with a narrower distribution than the nonimplanted samples. This reduction in size is also believed to be due to the "sputtering" effect caused by carbon implantation.

Figures 2a and $\mathrm{b}$ show FESEM images after CNT growth for samples with and without carbon implantation, respectively. Both images show that the presence of CNTs correlates with the region where Ge nanocrystals are present. No CNTs were seen in regions of the sample where there were no nanocrystals present. These results
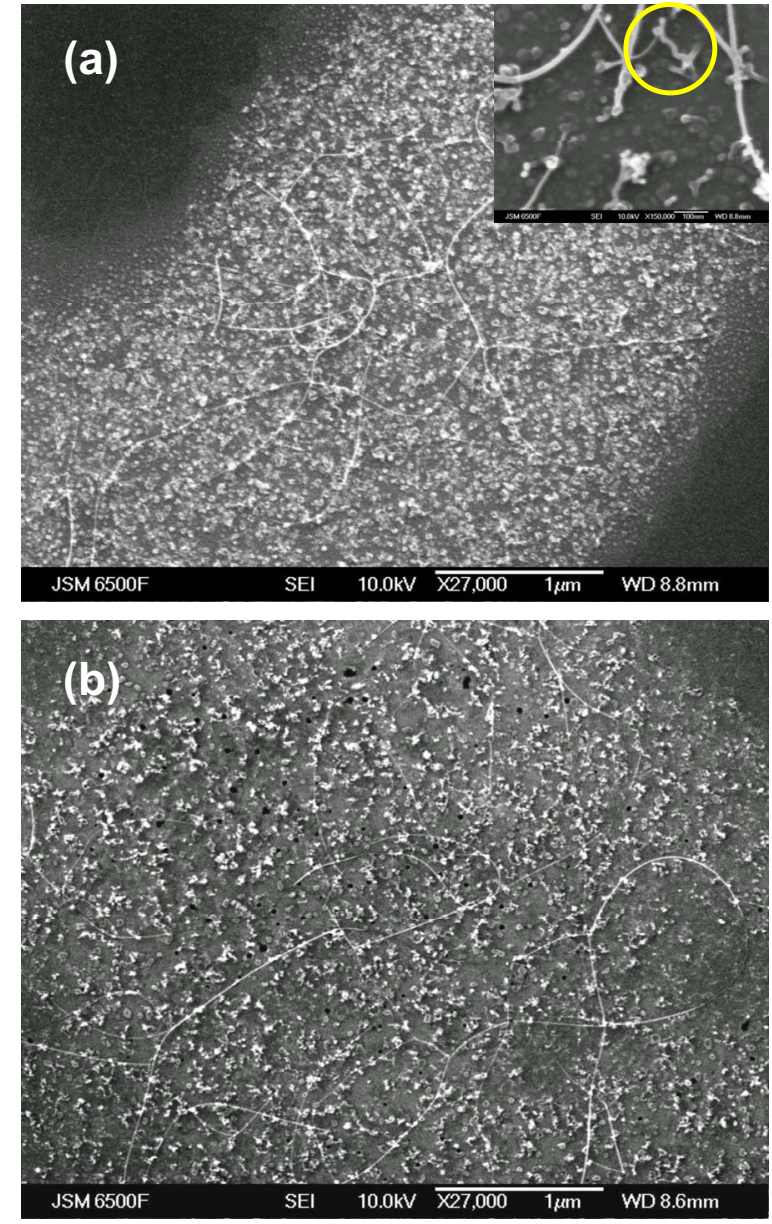

Figure 2. (Color online) FESEM images after CNT growth using Ge nanocrystals for (a) nonimplanted and (b) carbon-implanted samples. The CNTs were grown using a preanneal of $10 \mathrm{~min}$ at $900^{\circ} \mathrm{C}$ and a CNT growth of 20 $\min$ at $850^{\circ} \mathrm{C}$. Inset shows silica nanofibers near the Ge particles.

suggest that when implanted Ge nanocrystals are used, a carbon implantation is not essential for successful SWNT growth. This result contrasts with the results for our earlier growth method, where a carbon implantation was essential for successful SWNT growth on SiGe islands. ${ }^{12}$ Many short nanofibers are also seen in the region where Ge nanocrystals are present, as shown in the inset of Fig. 2a. Similar nanofibers were seen in our earlier work and were composed mainly of silica. ${ }^{12,13}$ These can be easily removed with an HF etch.

In Fig. 3, representative Raman spectra are presented for CNTs grown from samples with and without carbon implantation. The measured CNTs were grown using a preanneal at $900^{\circ} \mathrm{C}$ and a CNT growth step at $850^{\circ} \mathrm{C}$ for 20 min. All samples (insets) clearly show the radial breathing mode (RBM), indicating that SWNTs are present. For CNTs grown without carbon implantation, a small D-band peak is visible around $1320 \mathrm{~cm}^{-1}$, which can be attributed to the disorder in the CNTs (Fig. 3a). In contrast, the SWNTs grown on the carbon-implanted samples show no D-band peak (Fig. 3b). This indicates that SWNTs synthesized from carbon-implanted Ge nanocrystals have a low defect density and are thus of high quality. RBM peaks with a large number of different Raman shifts within the range from $408 \mathrm{~cm}^{-1}$ to the lower limit of $123 \mathrm{~cm}^{-1}$ imposed by our Raman notch filter have been observed. Assuming a standard formula for converting RBM Raman shift to CNT diameter, ${ }^{17}$ this indicates that the CNTs observed by Raman scattering have diameters in the range of $0.6-2.0 \mathrm{~nm}$.

The Raman measurements are supported by TEM measurements on a total of 38 CNTs from samples given a carbon implantation. 

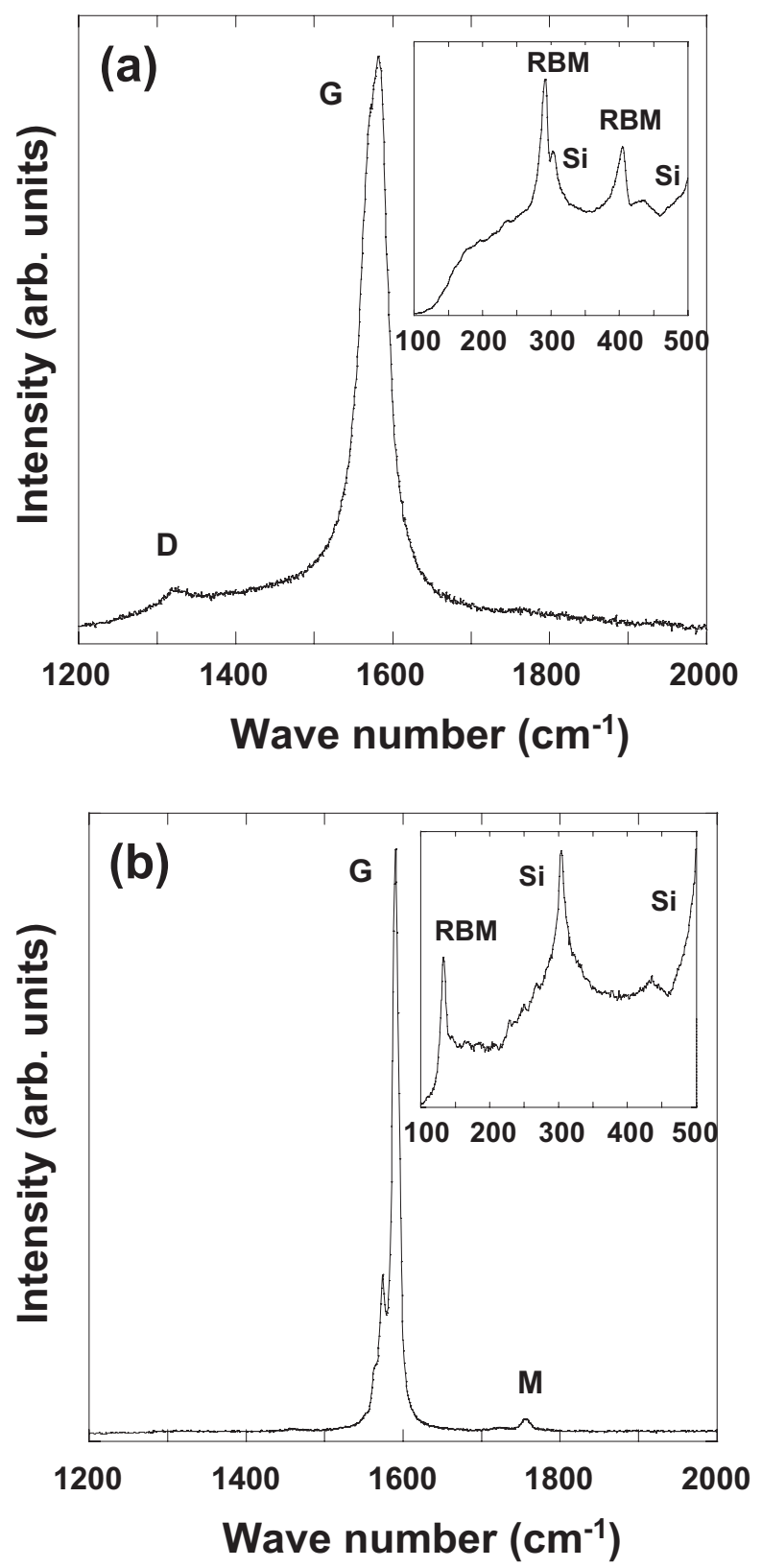

Figure 3. Raman spectra of CNTs grown from (a) nonimplanted and (b) carbon-implanted Ge nanocrystals. The CNTs were grown at $850^{\circ} \mathrm{C}$ after a preanneal at $900^{\circ} \mathrm{C}$

Representative TEM images and a histogram of the diameter distribution determined by analyzing the TEM images are shown in Fig. 4. In all cases the CNTs appeared as SWNTs. TEM measurements show a range of CNT diameters varying from 1.2 to $2.5 \mathrm{~nm}$. This compares to a range of 1.7-2.0 nm obtained from Raman measurements on the samples given a carbon implantation. These measurements indicate that the low frequency cutoff of the Raman notch filter does prevent thicker CNTs from being observed and that the true maximum diameter is approximately $2.5 \mathrm{~nm}$. Often, as shown in Fig. 4, the TEM images show CNTs attached to particles with a size of tens of nanometers, although we have not been able to determine if the CNTs originate from any specific features on these particles. EDX spectra show the presence of Ge and oxide in the nanoparticles. Other peaks of carbon and $\mathrm{Cu}$ come from the carboncoated $\mathrm{Cu}$ grid and a peak of $\mathrm{Si}$ comes from the $\mathrm{Si}$ substrate. No contamination from transition metals has been found.
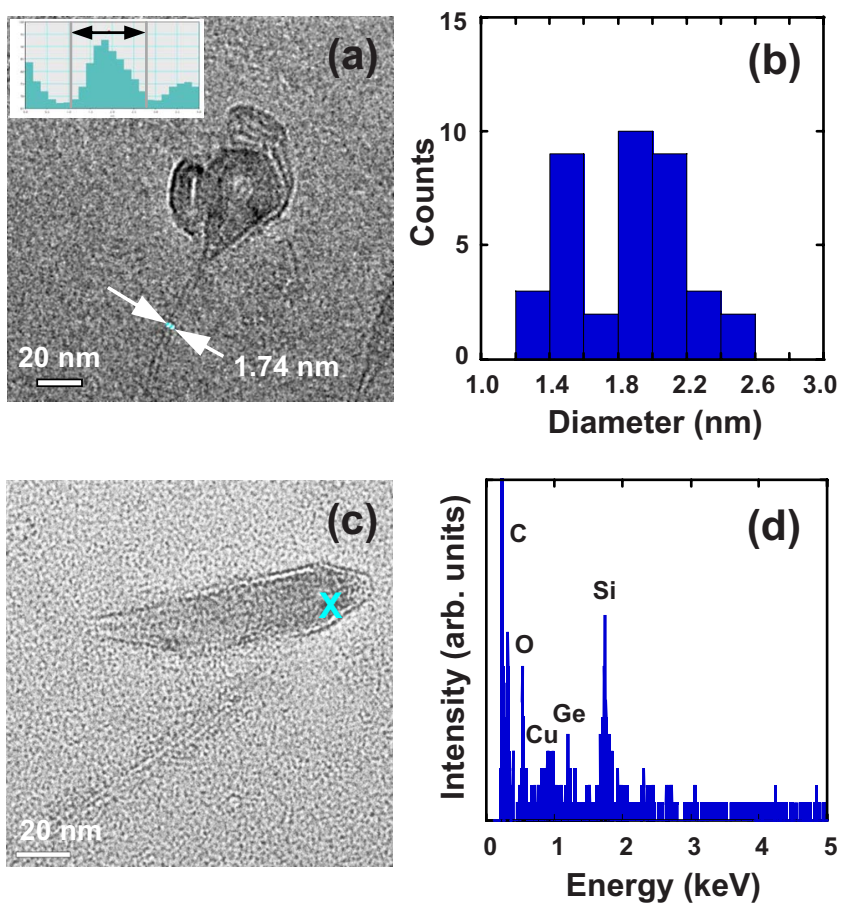

Figure 4. (Color online) (a) TEM image of SWNTs and carbon-implanted Ge nanocrystals using a preanneal at $900^{\circ} \mathrm{C}$ and a CNT growth at $850^{\circ} \mathrm{C}$. The inset shows line profile of the SWNT used to determine the diameter distribution. (b) A histogram of the diameter distribution of SWNTs. (c) TEM image of the SWNT and the carbon-implanted Ge nanocrystal for an EDX analysis. (d) EDX spectra of the carbon-implanted Ge nanocrystal.

Table I summarizes the CNT area densities for a range of preanneal and CNT growth temperatures for samples with and without carbon implantation. The highest CNT density, for both implanted and nonimplanted samples, is obtained by preannealing at $900^{\circ} \mathrm{C}$ followed by $\mathrm{CNT}$ growth at $850^{\circ} \mathrm{C}$. For these growth conditions there is no statistically significant advantage to the carbon implantation in terms of area density. However, the results show that successful CNT growth is achieved for a wider range of growth conditions, particularly higher growth temperatures, when the carbon implantation is present. At a CNT growth temperature of $850^{\circ} \mathrm{C}$, preanneal is essential for successful growth. However, if higher growth temperatures are used, successful growth can be attained without the preanneal step.

Table I. CNT area densities for different preanneal temperatures and CNT growth temperatures.

\begin{tabular}{|c|c|c|c|c|c|}
\hline \multicolumn{2}{|c|}{ Preanneal } & \multicolumn{2}{|c|}{ CNT growth } & \multicolumn{2}{|c|}{$\begin{array}{l}\text { CNT area density } \\
\left(\mu \mathrm{m} \text { in length } / \mu \mathrm{m}^{2}\right)\end{array}$} \\
\hline $\begin{array}{l}\text { Temperature } \\
\left({ }^{\circ} \mathrm{C}\right)\end{array}$ & $\begin{array}{l}\text { Time } \\
(\min )\end{array}$ & $\begin{array}{l}\text { Temperature } \\
\left({ }^{\circ} \mathrm{C}\right)\end{array}$ & $\begin{array}{l}\text { Time } \\
(\mathrm{min})\end{array}$ & Without $\mathrm{C}^{+}$ & With $\mathrm{C}^{+}$ \\
\hline 850 & 10 & 850 & 20 & $1.3 \pm 0.1$ & $1.2 \pm 0.3$ \\
\hline 900 & 10 & 850 & 20 & $3.5 \pm 1.0$ & $4.1 \pm 1.2$ \\
\hline 950 & 10 & 850 & 20 & $0.6 \pm 0.2$ & $2.0 \pm 0.6$ \\
\hline 1000 & 10 & 850 & 20 & No CNTs & $1.5 \pm 1.0$ \\
\hline 1000 & 5 & 850 & 20 & No CNTs & $2.7 \pm 0.8$ \\
\hline 1050 & 5 & 850 & 20 & No CNTs & $0.6 \pm 0.1$ \\
\hline 1100 & 5 & 850 & 20 & No CNTs & No CNTs \\
\hline N/A & N/A & 850 & 20 & No CNTs & No CNTs \\
\hline N/A & N/A & 900 & 20 & No CNTs & $0.4 \pm 0.1$ \\
\hline N/A & N/A & 950 & 20 & $1.6 \pm 0.5$ & $3.2 \pm 2.6$ \\
\hline N/A & N/A & 1000 & 20 & No CNTs & No CNTs \\
\hline
\end{tabular}




\begin{tabular}{|c|c|c|c|c|}
\hline \multirow{2}{*}{$\begin{array}{l}\mathrm{H}_{2} \text { anneal } \\
\text { temperature } \\
\left({ }^{\circ} \mathrm{C}\right)\end{array}$} & \multicolumn{2}{|c|}{$\begin{array}{l}\text { Nanocrystal density } \\
\quad\left(\text { particles } / \mu \mathrm{m}^{2}\right)\end{array}$} & \multicolumn{2}{|c|}{$\begin{array}{l}\text { CNT area density after growth } \\
\left(\mu \mathrm{m} \text { in length } / \mu \mathrm{m}^{2}\right)\end{array}$} \\
\hline & Without $\mathrm{C}^{+}$ & With $\mathrm{C}^{+}$ & Without $\mathrm{C}^{+}$ & With $\mathrm{C}^{+}$ \\
\hline As formed & $460 \pm 30$ & $64 \pm 18$ & N/A & N/A \\
\hline 900 & $30 \pm 6$ & $57 \pm 8$ & $3.5 \pm 1.0$ & $4.1 \pm 1.2$ \\
\hline 950 & $16 \pm 7$ & $40 \pm 4$ & $0.6 \pm 0.2$ & $2.0 \pm 0.6$ \\
\hline 1000 & $3.6 \pm 1.6$ & $38 \pm 8$ & No CNTs & $1.5 \pm 1.0$ \\
\hline
\end{tabular}

To investigate the role of preanneal in the growth process, AFM images of samples with and without carbon implantation were recorded immediately after a preanneal step. Table II summarizes the key findings. Samples without a carbon implantation show a drastic reduction in Ge nanocrystal density during the preanneal, which continues as the preanneal temperature increases and almost no Ge nanocrystals are present after preanneal at $1000^{\circ} \mathrm{C}$. Typical SEM images after preanneal are presented in Fig. 5 for samples without the carbon implantation and show the reduction in Ge nanocrystal density on increasing the preanneal temperature from 900 to $950^{\circ} \mathrm{C}$. The reduction in Ge nanocrystal density at high preanneal temperatures is most likely related to the melting point of $\mathrm{Ge}\left(937^{\circ} \mathrm{C}\right)$. The reduction in the Ge nanocrystal density is also associated with a
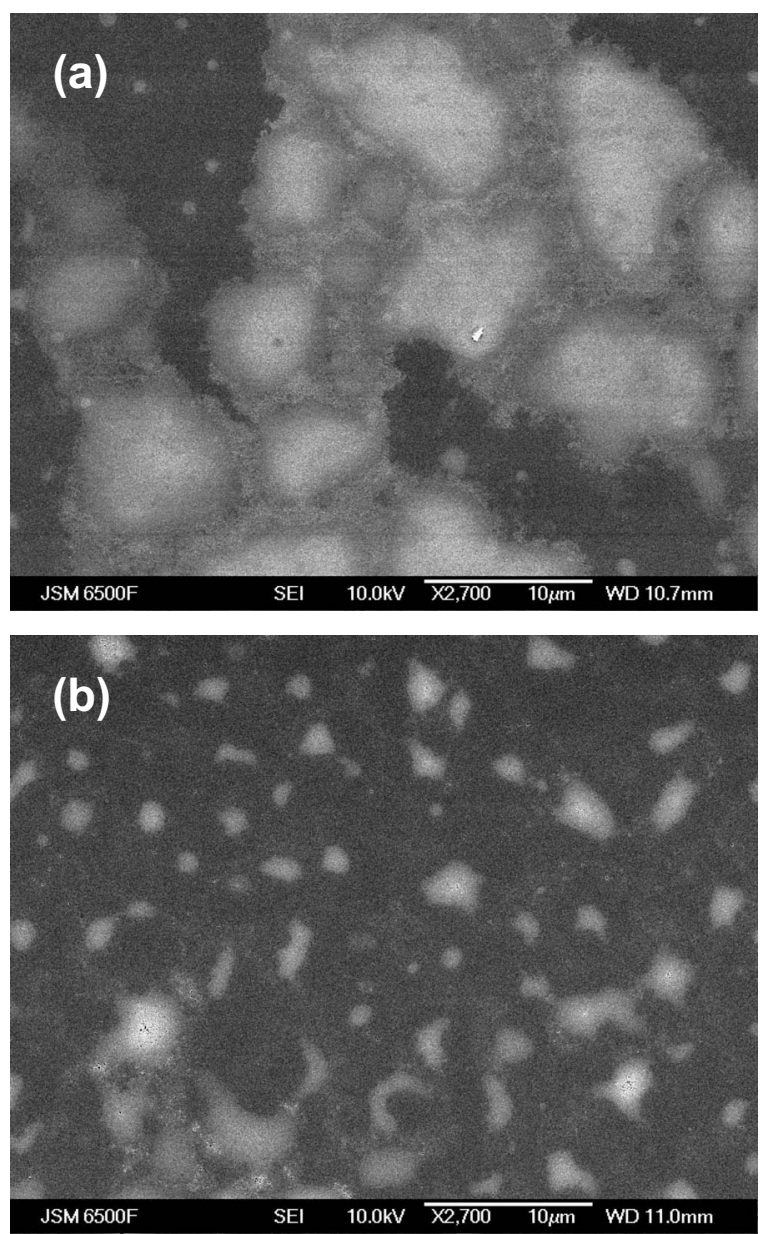

Figure 5. FESEM images just after $\mathrm{H}_{2}$ anneal of $10 \mathrm{~min}$ (a) at 900 and (b) $950^{\circ} \mathrm{C}$ for nonimplanted Ge nanocrystals. reduction in the proportion of larger nanocrystals (larger than $2 \mathrm{~nm}$ in diameter). AFM results show that the particle size distributions for samples with and without a carbon implantation and annealed at 900 and $950^{\circ} \mathrm{C}$ are similar (not shown). The preanneal has much less effect on carbon-implanted samples, which show little change in density and particle size distribution as the preanneal temperature is increased from 900 to $1000^{\circ} \mathrm{C}$.

Table II also shows a well-defined process window for CNT growth. The CNT area density is directly proportional to the $\mathrm{Ge}$ nanoparticle density at high preanneal temperatures for samples both with and without carbon implantation. This result suggests that $\mathrm{Ge}$ nanoparticles are the nucleation sites for the CNT growth. Almost all Ge nanoparticles are changed into liquid droplets over $900^{\circ} \mathrm{C}$ due to the melting-point reduction in nanoparticles ${ }^{18}$ and CNTs are synthesized from the Ge droplets in which the carbon feedstock is dissolved.

The hydrogen preanneal is effective in increasing the CNT area density and is critical for CNT growth from semiconductor particles. We believe that the hydrogen preanneal step is required to reduce oxide on the surface of the nanocrystals. While a chemical or thermal oxidation was not deliberately carried out before CNT growth, there would undoubtedly have been a native oxide present on the surface of both the Si substrate and the Ge nanocrystals, as indicated by the presence of silica nanofibers (Fig. 2a) and an oxide peak in the EDX spectrum (Fig. 4d). Our method does not require oxidation in air to activate the semiconductor particles, whereas Takagi et al. ${ }^{14}$ mentioned that it was the key requirement for CNT growth from semiconductor particles.

In our earlier growth method using SiGe islands, a carbon implantation was a prerequisite for CNT growth, ${ }^{12}$ whereas for implanted Ge nanocrystals CNT growth is possible without carbon implantation (Table I). This result suggests that Ge implantation into $\mathrm{SiO}_{2}$ and $\mathrm{N}_{2}$ anneal is a more successful method of producing nanocrystals of a size suitable for CNT growth. Nevertheless, the carbon implantation is very beneficial to CNT growth as it significantly broadens the process window for successful CNT growth and increases the CNT area density. In particular, it enables a preanneal up to temperatures as high as $1050^{\circ} \mathrm{C}$. For the carbon-implanted samples there is little reduction in Ge nanocrystal density as the preanneal temperature increases, in sharp contrast with samples without carbon implantation (Table II). This suggests that the carbon implantation might increase the melting point through the formation of a $\mathrm{Ge}_{1-y} \mathrm{C}_{y}$ alloy. This hypothesis is supported by the phase diagram of the $\mathrm{Ge}-\mathrm{C}$ system presented by Scace and Slack, ${ }^{19}$ which indicates that the presence of a small percentage of carbon has a strong effect on raising the melting point of Ge. Furthermore, Kanazawa et al. ${ }^{20}$ demonstrated that $\mathrm{Ge}_{1-y} \mathrm{C}_{y}$ alloys can be successfully formed by carbon implantation into Ge. An alternative, albeit less likely, explanation may be that the role of the carbon implantation in suppressing the agglomeration of Ge nanocrystals is physical. The lower initial nanocrystal density and the higher surface roughness caused by ion implantation may act to reduce agglomeration. ${ }^{2}$

The CNT area density of $4.1 \pm 1.2 \mu \mathrm{m}$ in length $/ \mu \mathrm{m}^{2}$ shown in Table I is comparable to densities reported for CNT-FET fabrication. For example, many groups ${ }^{22,23}$ have reported experimental CNTFETs fabricated with SWNT area densities of less than $1.5 \mu \mathrm{m}$ in length/ $\mu \mathrm{m}^{2}$. The CNT density achieved in this work is satisfactory for CNT-FET-based applications in sensors, logic, and memory devices. However, for application as SWNT via interconnects, much lower process temperature and higher CNT densities are required. The use of techniques already developed to reduce the growth temperature of CNTs using an Fe catalyst, e.g., $\mathrm{C}_{2} \mathrm{H}_{2}$ thermal CVD or oxygen-assisted plasma-enhanced CVD, may well allow the maximum temperature to reduce toward the upper limit of $400^{\circ} \mathrm{C}$ required for via interconnects. $^{24,25}$ It is unclear whether high CNT densities will be achievable with a Ge catalyst, however, with $\mathrm{Fe}$ catalysts, densities vary strongly with growth conditions. Further research on the growth of SWNTs using Ge nanoparticles is therefore needed to investigate the effect of growth conditions on density. 


\section{Conclusion}

We have developed a growth method of SWNTs which is ideally suited to standard $\mathrm{Si}$ technology. The results indicate that Ge implantation into a $\mathrm{SiO}_{2}$ layer followed by a thermal anneal provides good control of nanocrystal size and delivers a well-controlled SWNT growth process. An SWNT area density of $4.1 \pm 1.2 \mu \mathrm{m}$ in length $/ \mu \mathrm{m}^{2}$ was obtained from the Ge nanocrystals under the optimum growth conditions. A carbon-ion implantation after Ge nanocrystal formation significantly enhances the CVD process operating window, the area density, and the quality of the SWNTs. Nonetheless, carbon implantation is not essential for the growth. It may therefore be possible to optimize the current process or to develop a new Ge-based process which does not require carbon implantation to obtain high quality SWNTs.

\section{Acknowledgments}

The Ion Beam Centre at the University of Surrey is gratefully acknowledged for ion implantation. This work was supported by the EPSRC and the European Union (SINANO). D.C.S. thanks EPSRC for an Advanced Research Fellowship. We thank S. Wang and B. A. Cressey for technical support for TEM observations.

\section{References}

1. M. S. Dresselhaus and H. Dai, MRS Bull., 29, 237 (2004).

2. P. Avouris, J. Appenzeller, R. Martel, and S. J. Wind, Proc. IEEE, 91, 1772 (2003).

3. J. A. Misewich, R. Martel, P. Avouris, J. C. Tsang, S. Heinze, and J. Tersoff, Science, 300, 783 (2003).

4. R. Saito, G. Dresselhaus, and M. S. Dresselhaus, Physical Properties of Carbon Nanotubes, World Scientific, Singapore (1998).

5. T. Rueckes, K. Kim, E. Joselevich, G. Y. Tseng, C. L. Cheung, and C. M. Lieber, Science, 289, 94 (2000).
6. M. Horibe, M. Nihei, D. Kondo, A. Kawabata, and Y. Awano, Jpn. J. Appl. Phys., Part 1, 44, 5309 (2005)

7. D. S. Chung, S. H. Park, H. W. Lee, J. H. Choi, S. N. Cha, J. W. Kim, J. E. Jang, K. W. Min, S. H. Cho, M. J. Yoon, et al., Appl. Phys. Lett., 80, 4045 (2002).

8. M. Haque, K. Teo, N. Rupensinghe, S. Ali, I. Haneef, S. Maeng, J. Park, F. Udrea, and W. Milne, Nanotechnology, 19, 025607 (2008).

9. B. L. Sharma, Diffusion in Semiconductors, Trans. Tech., Germany (1970).

10. M. Kusunoki, M. Rokkaku, and T. Suzuki, Appl. Phys. Lett., 71, 2620 (1997).

11. S. Botti, R. Ciardi, M. L. Terranova, S. Piccirillo, V. Sessa, M. Rossi, and M. V. Antisari, Appl. Phys. Lett., 80, 1441 (2002).

12. T. Uchino, K. N. Bourdakos, C. H. de Groot, P. Ashburn, M. E. Kiziroglou, G. D. Dilliway, and D. C. Smith, Appl. Phys. Lett., 86, 233110 (2005).

13. T. Uchino, K. N. Bourdakos, C. H. de Groot, P. Ashburn, S. Wang, M. E. Kiziroglou, G. D. Dilliway, and D. C. Smith, in Proceedings of the Conference on Nanotechnology, IEEE, Vol. 2, p. 649 (2005).

14. D. Takagi, H. Hibino, S. Suzuki, Y. Kobayashi, and Y. Homma, Nano Lett., 7, 2272 (2007).

15. K. S. Min, K. V. Shcheglov, C. M. Yang, H. A. Atwater, M. L. Brongersma, and A. Polman, Appl. Phys. Lett., 68, 2511 (1996).

16. See http://rsb.info.nih.gov/ij/, last accessed June 2, 2009.

17. A. Jorio, C. Fantini, M. S. S. Dantas, M. A. Pimenta, A. G. S. Filho, G. G. Samsonidze, V. W. Brar, G. Dresselhaus, M. S. Dresselhaus, A. W. Swan, et al., Phys. Rev. B, 66, 115411 (2002).

18. M. Takagi, J. Phys. Soc. Jpn., 9, 359 (1954).

19. R. I. Scace and G. A. Slack, J. Chem. Phys., 30, 1551 (1959),

20. Y. Kanazawa, K. Katayama, K. Nozawa, T. Saitoh, and M. Kubo, Jpn. J. Appl. Phys., Part 1, 40, 5880 (2001).

21. L. Delzeit, B. Chen, A. M. Cassell, R. Stevens, C. Nguyen, and M. Meyyappan, Chem. Phys. Lett., 348, 368 (2001).

22. L. Rispal and U. Schwalke, IEEE Electron Device Lett., 29, 1349 (2008).

23. L. Durrer, T. Helbling, C. Zenger, A. Jungen, C. Stampfer, and C. Hierold, Sens. Actuators B, 132, 485 (2008).

24. M. Cantoro, S. Hofmann, S. Pisana, V. Scardaci, A. Parvez, C. Ducati, A. Ferrari, A. Blackburn, K. Wand, and J. Robertson, Nano Lett., 6, 1107 (2006).

25. G. Zhang, D. Mann, L. Zhang, A. Javey, Y. Li, E. Yenilmez, Q. Wang, J. P. McVittie, Y. Nishi, J. Gibbons, et al., Proc. Natl. Acad. Sci. U.S.A., 102, 16141 (2005). 